\title{
Antifungal Activity of ZnO Thin Films Prepared by Glancing Angle Deposition
}

Patrícia Pereira-Silva ${ }^{1,2,3}$, Augusto Costa-Barbosa ${ }^{1,2}$, Diogo Costa ${ }^{1,2,3}$, Marco S. Rodrigues ${ }^{3}$,

Pedro Carvalho $^{3}$, Joel Borges ${ }^{3 *}$, Filipe Vaz $^{3 * *}$, Paula Sampaio $^{1,2}$

${ }^{1}$ Centre of Molecular and Environmental Biology (CBMA), Department of Biology, University of Minho, 4710-057 Braga, Portugal

${ }^{2}$ Institute of Science and Innovation for Bio-Sustainability (IB-S), University of Minho, Portugal

${ }^{3}$ Centre of Physics (CFUM), University of Minho, 4800-019 Guimarães, Portugal

Corresponding authors:

*Joel Borges; e-mail: joelborges@ fisica.uminho.pt

**Filipe Vaz; e-mail: fvaz@ fisica.uminho.pt

\section{Highlights}

- Zinc Oxide thin films were deposited by reactive magnetron sputtering;

- Inclined columns changed the thin films' surface porosity;

- Sputtering incidence angle affects microstructure and antifungal properties;

- Mesoporous thin films improved the antifungal properties against Candida albicans; 


\title{
Antifungal Activity of ZnO Thin Films Prepared by Glancing Angle Deposition
}

Patrícia Pereira-Silva ${ }^{1,2,3}$, Augusto Costa-Barbosa ${ }^{1,2}$, Diogo Costa ${ }^{1,2,3}$, Marco S. Rodrigues ${ }^{3}$,

Pedro Carvalho ${ }^{3}$, Joel Borges ${ }^{3 *}$, Filipe Vaz $^{3 * *}$, Paula Sampaio ${ }^{1,2}$

${ }^{1}$ Centre of Molecular and Environmental Biology (CBMA), Department of Biology, University of Minho, 4710-057 Braga, Portugal

${ }^{2}$ Institute of Science and Innovation for Bio-Sustainability (IB-S), University of Minho, Portugal

${ }^{3}$ Centre of Physics (CFUM), University of Minho, 4800-019 Guimarães, Portugal

Corresponding authors:

*Joel Borges; e-mail: joelborges@ fisica.uminho.pt

**Filipe Vaz; e-mail: fvaz@ fisica.uminho.pt

\begin{abstract}
Thin films of zinc oxide $(\mathrm{ZnO})$ were produced by reactive $\mathrm{DC}$ magnetron sputtering with sputtering angles of $\alpha=0^{\circ}, 40^{\circ}, 60^{\circ}$ and $80^{\circ}$ (glancing angle deposition configuration), aiming to be tested against the opportunist pathogenic fungus Candida albicans. The results showed the formation of stoichiometric $\mathrm{ZnO}$ thin films, with inclined columns for incidence angles equal to or more than $40^{\circ}$. All thin films presented high transparency in the visible range above the bandgap region (near $380 \mathrm{~nm}$ ). The deposition conditions gave rise to a three-fold increase of the surface porosity with the increment of the incidence angle. Noteworthy, is the formation of different types of pores distributions, from micro-, through meso-, to macropores. Regarding the biological effect, the thin films produced with inclined columns presented a significant antifungal activity, with the inhibition of viable cell growth by $68 \%$. Moreover, the formation of mesoporous films enhanced the antifungal properties of $\mathrm{ZnO}$ thin films against Candida albicans. The overall behaviour indicates that these thin films are promising candidates to be applied in antimicrobial surfaces, as well as to be used in further studies to determine the molecular mechanisms involved in the antimicrobial action of $\mathrm{ZnO}$.
\end{abstract}




\section{Keywords}

Glancing angle deposition; Zinc oxide; Microstructure; Surface porosity; Antifungal surfaces;

Candida albicans. 


\section{Introduction}

Microbial infectious diseases are still a major cause of morbidity and mortality [1], that has drawn public attention worldwide, as a human health threat, which leads to economic and social impacts [2]. Most of the life-threatening microbial infections are acquired in healthcare settings, like hospitals and intensive care units, being referred as Nosocomial Infections or HealthcareAssociated Infections (HCAI). These HCAI affect nearly $10 \%$ of patients (during and after hospitalization), health professionals and visitors, and are responsible for 3 million deaths per year, only in the European Union [3]. Bacteria are the main responsible pathogen accounting for $90 \%$ of nosocomial infections, followed by fungi and viruses [4]. However, fungal infections are growing considerably in the last decades and present a high mortality rate [5].

Candida spp. is a group of opportunist fungal pathogens that is the fourth most common cause of nosocomial bloodstream infections. The most frequent and responsible species for the majority of superficial and systemic infections is Candida albicans [6-8]. Worldwide, there is a continuous increase in resistance of Candida spp. to first-line and second-line antifungal treatment agents [9]. In the United States, it is estimated that 46.000 healthcare-associated Candida infections occur among hospitalized patients each year and during their hospitalization. Moreover, $30 \%$ of patients with candidemia, including drug-resistance Candida, end up dying. So, the Centre for Disease Control and Prevention estimates that these infections add 3 to 13 more days of hospitalization [10]. In Portugal, the incidence of disseminated candidiasis is even higher than the average in the United States and Europe [11,12].

The principal source of infectious agents is the direct contact with patients, usually by the hands of healthcare workers and by the medical equipment [13]. But since the hospital environment is susceptible to be contaminated, common surfaces can act as a niche to microbes' adhesion and colonization, allowing the spread of nosocomial infections [14,15]. Those surfaces comprise room 
door handles, keyboards and taps, stethoscopes, ward fabrics and plastics, healthcare worker's pens and telephones [16]. Consequently, healthcare facilities need to be meticulously disinfected to destroy microbes, nevertheless traditional antimicrobial agents are extremely irritant and toxic to humans, and have a higher production cost and weak activity [1,17].

Taking all the above into account, nanomaterials are gaining significant interest to be included in antimicrobial surfaces. Since their dimensions are typically from tens to a few hundred nanometres, the physicochemical and structural properties are modified, which increases their activity compared to the bulk form $[18,19]$. In general, engineered nanomaterials have unique electrical, thermal, and mechanical properties that can be tuned for the desired applications. Currently, researchers are exploring metal oxide nanoparticles as antimicrobial agents, since they possess greater durability, heat resistance, negligible toxicity, higher stability, and selectivity when compared to organic ones, even in small amounts [19].

Zinc oxide $(\mathrm{ZnO})$ has been described as a versatile, functional, and promising inorganic material that can be used in different applications. It is a II-VI group semiconductor material, n-type, with a wide band gap, in the near-UV spectrum ( $\sim 3.3 \mathrm{eV}$ at room temperature), and large excitonic binding energy $\sim 60 \mathrm{meV}$ [20]. Its band gap has a significant effect on the electrical conductivity and optical absorption, making it transparent in the visible light region. Moreover, $\mathrm{ZnO}$ is listed as safe by the US Food and Drug Administration (21CFR182.8991) [21] and classified as a lowcost material, easy to process, abundant in nature, biosafe, biocompatible, non-toxic and, more important in this case, it presents antimicrobial activity against both bacteria [22] and fungi [23]. Besides, $\mathrm{ZnO}$ was shown to be a better antibacterial agent compared to the highly studied titanium dioxide $\left(\mathrm{TiO}_{2}\right)$ [24]. Consequently, there are several studies related to the antimicrobial activity of 
$\mathrm{ZnO}$ produced by different methods [25-28] and in its pure form, with different structures [29], in composites with other materials [30], and doped with other elements (e.g. silver) [31].

Colloidal $\mathrm{ZnO}$ nanoparticles are the most frequently studied morphology. Although there are different factors that affect their action, several studies proved that antimicrobial activity seems to be closely related to their surface properties [32]. $\mathrm{ZnO}$ has been used in commercial dermatological applications, such as creams, lotions, ointments, and mouthwashes, in order to prevent pathogens growth [33]. However, these $\mathrm{ZnO}$ nanoparticles also proved to have a negative impact on human health and in the environment. To human health, the major concerns are the toxicity, biodistribution and bioaccumulation of the nanoparticles [34-37]. On the environment, these nanoparticles accumulate in ecosystems (e.g. water and soils) posing threats to living organisms $[38,39]$.

In the last few years, there has been a growing interest in the development of antimicrobial coatings based on thin films, as an alternative approach to $\mathrm{ZnO}$ nanoparticles [16]. These $\mathrm{ZnO}$ thin films may present different chemical compositions (stoichiometries), and microstructures, like the crystalline domains size (grain size), morphology, roughness and porosity. The modification of these parameters allows the achievement of a wide range of thin films' properties, to apply in functional coatings [40]. Thus, it is believed that the development of thin films for antimicrobial surfaces to reduce microbial loads on a surface would play an important role in reinforcing the hygiene regime of a healthcare environment. Consequently, removing the ability of a surface to act as a microbial reservoir would certainly contribute to breaking the "nosocomial infection loop", leaving the problem of person-to-person transmission, which can be prevented by appropriate hand washing and the use of alcohol hand rubs, by healthcare workers [16]. Ideally, these antimicrobial surfaces should be hard-wearing, permanent, and suitable for hospital conditions. 
Nowadays, magnetron sputtering is one of the most effective process for the deposition of various thin films materials [41,42]. Furthermore, the introduction of Glancing Angle Deposition (GLAD) configuration results in the production of nanostructured thin films with distinct (micro)structural features and tailored density/porosity [43,44]. The basic principle of this mechanism is that the evaporated/sputtered individual atoms, from the target, reach the substrate surface at an incidence angle $\alpha$, and microscopic nuclei are randomly deposited. Consequently, the region behind the nucleus does not receive any further sputtered particles, since this region falls in the "shadow" of the nucleus. Thus, the atoms will only be deposited onto the nucleus and the columnar structure develops, with some columns growing faster than others, leading to shadowing of the slower growing columns. Eventually, some of the columns stop growing and the other ones only grow on the top [45-48]. The formed columns are titled toward the incident flux direction and can be sculptured into different morphologies, such as helices, inclined and vertical pillars (with variable diameter), zig-zags, and square spirals [49-53]. All these efforts make the GLAD technique excellent for design and device optimization for the development of sensors and optical devices, among others [45,54-58].

In the present work, $\mathrm{ZnO}$ thin films were prepared by reactive $\mathrm{DC}$ magnetron sputtering with inclined columns. Taking advantage of the GLAD technique, the films were deposited at different incidence angles $\left(\alpha=0^{\circ}, 40^{\circ}, 60^{\circ}\right.$ and $\left.80^{\circ}\right)$, to modify the thin films' surface porosity. The opportunist pathogenic fungus Candida albicans was used to evaluate the influence of deposition angle on the $\mathrm{ZnO}$ thin films' microstructure and antifungal activity.

\section{Experimental Details}

\subsection{Production and characterization of $\mathrm{ZnO}$ thin films}


The $\mathrm{ZnO}$ thin films were deposited by reactive DC magnetron sputtering in a custom-made highvacuum $\left(10^{-4} \mathrm{~Pa}\right)$ deposition system, equipped with a GLAD sample holder (Fig. 1a) [59]. The thin films were deposited on glass lamellae (ISO8037) and in monocrystalline silicon (Si) wafers with (100) orientation. Initially, the substrates were cleaned with ethanol $96 \%$ and dried with cleanroom paper. Then, the substrates were subjected to plasma treatment, performed in a Diener (Zepto Type Model) equipment, to increase the thin film's adhesion. The base pressure of the system was $20 \mathrm{~Pa}$ and the first plasma treatment was performed with an $\mathrm{O}_{2}$ partial pressure of 80 Pa for 5 minutes, in order to remove possible organic contaminations at the substrate' surface. To eliminate remaining impurities and to activate the surface and thus improve the adhesion of the thin film, the substrates were treated with an Ar plasma, with the partial pressure of $80 \mathrm{~Pa}$ for 15 minutes.

While thin films deposited on glass were used for studies related to optical and antifungal properties, the ones deposited on $\mathrm{Si}$ were subjected to morphological, structural and chemical characterization. A high purity $(99.99 \%)$ and rectangular $\left(200 \times 100 \times 6 \mathrm{~mm}^{3}\right)$ zinc target was used as a cathode for the thin films production, being placed over a magnetron that gives an average magnetic field of $220 \mathrm{mT}$ above erosion track. The substrates were placed on a static substrate holder at approximately $11 \mathrm{~cm}$ from the target. The main changed parameter was the incidence angle $\left(0^{\circ}\right.$ - corresponding to a flux of sputtered atoms perpendicular to the substrate; $40^{\circ}, 60^{\circ}$ and $80^{\circ}$ ) of sputtered particles flux $(\alpha)$, in order to obtain inclined columns, and thus different microstructures (Fig. 1b). Before the depositions, the sputtering chamber was pumped down to $5.0 \times 10^{-4} \mathrm{~Pa}$. The thin films deposition occurred at a working pressure of $4.5 \times 10^{-1} \mathrm{~Pa}$, using an $\operatorname{argon}\left(\mathrm{Ar}\right.$, working gas) and oxygen $\left(\mathrm{O}_{2}\right.$, reactive gas) atmosphere. The $\mathrm{Ar}$ and $\mathrm{O}_{2}$ flow were kept constant during the deposition using gas flows of 25 and $13 \mathrm{sccm}$, corresponding to partial 
pressures of $3.5 \times 10^{-1} \mathrm{~Pa}$ and $1.0 \times 10^{-1} \mathrm{~Pa}$, respectively. All depositions started at room temperature, not overcoming $100{ }^{\circ} \mathrm{C}$ during deposition (measured with a thermocouple, type $\mathrm{K}$, placed on the back surface of the substrate). The deposition time for each incidence angle was adjusted according to previous works [59] so that the thickness would be as close as possible among the films. Thus, the deposition times were $18,30,42$ and $64 \mathrm{~min}$ for the incidence angles of $0^{\circ}, 40^{\circ}, 60^{\circ}$ and $80^{\circ}$, respectively. The applied DC current density was $50 \mathrm{~A} \mathrm{~m}^{-2}$ and the (negative) target potential was $400 \mathrm{~V}$.

The in-depth chemical composition profile was evaluated by Rutherford Backscattering Spectrometry (RBS) with a Van de Graff accelerator. The measurements were made in a small chamber, where three detectors were installed: standard at $140^{\circ}$ and two pin-diode detectors located symmetrically to each other, both at $165^{\circ}$ (detector 3 on the same side as standard detector 2 ). Spectra were collected using $2 \mathrm{MeV}^{4} \mathrm{He}^{+}$, and $1.4 \mathrm{MeV} \mathrm{H} \mathrm{H}^{+}$beams at normal incidence. The obtained RBS data were analysed with IBA DataFurnace NDF v9.6i [60], and the double scattering and pileup were calculated with the algorithms given in N. P. Barradas et al. (2005) [61] and in N. P. Barradas et al. (2006) [62], respectively. The crystalline structure of the $\mathrm{ZnO}$ thin films was analysed by X-Ray diffraction (XRD), with $\mathrm{CuK} \alpha$ radiation $(\lambda=0.15406 \mathrm{~nm})$, operating in a grazing incidence mode at an angle of $2.5^{\circ}$. The diffractograms were recorded between $2 \theta$ angles from $30^{\circ}$ to $70^{\circ}$, with a scanning step size of $0.04^{\circ}$, and step time of $1 \mathrm{~s}$. This analysis was performed in a Bruker D8 Discover Diffractometer. Scanning Electron Microscopy (SEM) was performed to study the microstructure of the thin films, using a NanoSEM - FEI Nova 200 (FEG/SEM) microscope operating at $10 \mathrm{keV}$. The top-view micrographs of GLAD thin films were analysed in MATLAB to study the porosity. A MATLAB algorithm was written to estimate the surface porosity, by calculating the percentage of dark pixels. This algorithm included the locally 
adaptive threshold function "adaptthresh", from the image processing toolbox, to be more sensitive to the heterogeneous film surface, and the same parameters were used for all micrographs [59]. The analysis of the optical response of the $\mathrm{ZnO}$ thin films was performed in transmittance mode, where the spectral range measured was between 300 and $800 \mathrm{~nm}$, using a Shimadzu UV2450-PC UV-Vis spectrophotometer.

\subsection{ZnO thin films' antifungal activity}

The antifungal activity of $\mathrm{ZnO}$ thin films was evaluated through the incubation with the pathogenic opportunistic fungus Candida albicans. Firstly, the $\mathrm{ZnO}$ thin films (in glass lamellae of $20 \times 25$ $\mathrm{mm}^{2}$ ) were sterilized with ethanol $70 \%(\mathrm{v} / \mathrm{v})$, for 2 hours and rinsed with sterile deionized water, in order to remove the possible impurities and microorganisms attached to their surfaces. Additionally, a glass lamella (with the same size of the thin films) was used as a control for the substrate action. Then, a pre-culture of Candida albicans cells was prepared by picking a colony and inoculating in $20 \mathrm{~mL}$ of YPD (1\% w/v yeast extract, $2 \% \mathrm{w} / \mathrm{v}$ peptone, and $2 \% \mathrm{w} / \mathrm{v}$ dextrose). This pre-culture was incubated in a Benchtop Shaking Incubator 222DS, with 120 rpm in orbital agitation, at $30^{\circ} \mathrm{C}$, overnight.

After the growth of the pre-culture, Candida albicans cells were transferred to a new culture tube, with $20 \mathrm{~mL}$ of YPD, at an optical density (O.D. $600 \mathrm{~nm}$ ) of 0.1 , corresponding to $2 \times 10^{6}$ fungus cells per millilitre. The previous sterilized thin films were added to this culture tubes and were incubated at $30{ }^{\circ} \mathrm{C}$ and shaking at $120 \mathrm{rpm}$. The growth was monitored during 25 hours with the evaluation of O.D. values at $600 \mathrm{~nm}$, in a Spectronic 20 spectrophotometer. In order to evaluate the interaction of the cells with the thin films, in a liquid medium, two timepoints were selected: 8 and 25 hours, since the first corresponds to the microbial exponential growth phase and the last one to the latter 
stationary growth phase. At these incubation time, the number of Colony Forming Units (CFUs) was counted to estimate the number of viable yeast cells after the interaction with each thin film. For each thin film, three independent replicates were done, and the data were analysed by GraphPad Prism 6 Software (GraphPad Software, Inc., La Jolla, CA, USA). The specific growth rate was calculated through the slope of the logarithm of the O.D. value as a function of time. This trend line was constructed using the first four values of O.D., when cells were at exponential growth phase, and the data were analysed by a two-sided parametric unpaired T-test, with Welch's correction for different standard deviations, with $95 \%$ confidence level. CFUs data obtained from the incubation assay were analysed through a one-way ANOVA, with a $95 \%$ confidence level.

\section{Results and discussion}

\subsection{ZnO thin films characterization}

Zinc oxide thin films were deposited with the GLAD configuration, using different incidence angles, in order to obtain inclined columns and thus changes in their surface porosity, which are expected to improve the antimicrobial properties of the films. The stoichiometry of the films was confirmed by RBS analysis, which proved that the O/Zn ratio was very close to 1.0. The GLAD thin films' thickness was measured through the SEM micrographs obtained in cross-section that allowed the deposition rate calculation, all summarized in Table I.

Table I - Incidence angle, thickness, and deposition rate of the $\mathrm{ZnO}$ thin films.

\begin{tabular}{c|ccc}
\hline Condition & Incidence angle $\boldsymbol{\alpha}\left(^{\circ}\right)$ & Thickness $(\boldsymbol{\mu m})$ & Deposition Rate $(\mathbf{n m} / \mathbf{m i n})$ \\
\hline $\mathbf{Z n O ~ 0}^{\circ}$ & 0 & 0.54 & 30 \\
$\mathbf{Z n O ~ 4 0}$ & 40 & 0.65 & 22 \\
$\mathbf{Z n O ~ 6 0}^{\circ}$ & 60 & 0.73 & 17 \\
$\mathbf{Z n O ~ 8 0}^{\circ}$ & 80 & 0.62 & 10
\end{tabular}


Regarding the optical behaviour, the $\mathrm{ZnO}$ thin films have high transparency to visible light, with a cut-off wavelength in the near-UV, close to $380 \mathrm{~nm}$ (Fig. 2), as actually expected from this semiconductor material [63-65]. The sudden drop in the transmittance spectrum has the same profile for all thin films regardless of the incidence angle, which is related to the interband transitions in the $\mathrm{ZnO}$ film and defines the bandgap region. Above the bandgap wavelength, interference oscillations are observed due to multiple internal reflections between the film and the glass substrate. A closer look to the transmittance spectra seems to suggest that the "envelope" of interference fringes suffers some changes (reduction) as the incidence angle increases. This behaviour is surely related to the increase of the film's porosity (demonstrated later in this manuscript), that led to a density reduction and thus to a decrease of the effective refractive index of the material $[59,66]$.

The XRD results (Fig. 3) showed modifications among the samples produced using different incidence angles $\left(0^{\circ}, 40^{\circ}, 60^{\circ}\right.$ and $\left.80^{\circ}\right)$. It is important to mention that the XRD analysis was performed in grazing incidence mode, and thus the contribution of the substrate was not detected. The increase of the incidence angle led to the evolution of the crystalline structure of the thin films. The $\mathrm{ZnO}$ thin film prepared at an incidence angle of $0^{\circ}$ is a poorly crystalline film, while the ones prepared at incidence angles of $40^{\circ}$ and $60^{\circ}$ present a $\mathrm{ZnO}$-type hexagonal wurtzite structure, where the (002) orientation clearly prevails over the (103) plane (ICDD card No. 01-070-8070). The (002) peak is related to the strong preferential growth along this plane, as previously reported by Yang et al. [67]. Some authors claim that c-orientation of the $\mathrm{ZnO}$ crystals results from the highest atomic density found along (002) plane [68], parallel to the surface, while others associate the preferential orientation with the minimization of internal stress and surface energy [69]. However, 
increasing the incidence angle to $80^{\circ}$ induced a loss in crystallinity, meaning that higher incidence angles hinder the grain growth. This effect has been reported in the literature, mentioned as a crystallization degradation during deposition at oblique/glancing angles [66,70].

From the morphological analysis (SEM micrographs of Fig. 4), it is possible to observe that the films prepared with an incidence angle $(\alpha)$ of $0^{\circ}$ originated films with straight columns. Increasing $\alpha$ to $40^{\circ}$ some inclined columns started to appear, but being much more evident at $60^{\circ}$, and totally perceivable for the highest incidence angle, $\alpha=80^{\circ}$.

From the top-view images of the films (Fig. 5a), it can be verified that the increment of the incidence angle $(\alpha)$ led to surface modifications, namely an increase of the roughness and of the porosity. This modification can be explained not only by the type of columns growth but also by the well-known "self-shadowing" effect.

Contrary to other works $[49,50]$, the produced thin films did not show isolated columnar structures. Yet, it was possible to obtain different surface porosities by simply changing the incidence angle. The type of surface porosity of the thin films was calculated as proposed by Tamar et al. [71] and implemented by Rodrigues et al. [59], by producing thresholded black and white images (see Fig. $5 b$ ). The thin film prepared with $\alpha=0^{\circ}$ presented a surface porosity of $8 \%$, and its pores had an average Feret diameter of $5 \mathrm{~nm}$ (Fig. 5c). This film can be characterized as microporous, according to IUPAC's definition [72]. The same characterization was applied to the film prepared with an incidence angle of $\alpha=40^{\circ}$, although it presented a higher surface porosity value (11\%). Increasing the $\alpha$ to $60^{\circ}$ led once again to a surface porosity increase (13\%), but it was not significant in relation to the previous angle. However, this incidence angle allowed the formation of pores with Feret diameter between 5 and $50 \mathrm{~nm}$, thus being designated as a mesoporous thin film. Finally, the higher incidence angle $\left(\alpha=80^{\circ}\right)$ incremented the surface porosity to $23 \%$ and the pores revealed 
Feret diameters ranging from 5 to $200 \mathrm{~nm}$. This variation is explained by the existence of interconnected porosity due to the presence of a considerable number of grooves, with different sizes across the film, creating macropores. In general, this latter thin film is designated as an interconnected macroporous thin film.

All these results showed that the increment of the incidence angle promoted not only the increase of thin films' surface porosity but also the type of porosity. In fact, they developed micro-, mesoand macropores where the microbial cells can be disposed and adhere. It is believed that due to the higher surface area and predominance of a certain type of pores, these thin films will present significant differences in their antimicrobial activity.

\subsection{Evaluation of ZnO thin films' antifungal activity}

With the purpose of evaluating the applicability of the produced $\mathrm{ZnO}$ thin films as antimicrobial coatings/surfaces, they were incubated with cells of the pathogenic fungus $C$. albicans, in liquid medium (YPD) for 25 hours. Throughout the assay, the cellular growth was monitored and compared to a control group and to the glass control. The control group corresponded to the free growth of the cells (positive control) and the glass control corresponded to the growth of the cells in the presence of glass lamellae, with the same size as those where the thin films were deposited. The latter served as a control of substrate action. Since no significant differences were found between these two groups (data not shown), it means that the substrate (glass) does not exhibit any antifungal effect, thus all the experiments were compared only with the positive control.

Regarding the thin films, this assay showed a decrease in the O.D. values as soon as after 5 hours incubation, compared to the control, suggesting that all of them slowed down the fungal growth (Fig. 6a). However, the growth rate of the yeast culture showed that only the sample $\mathrm{ZnO} 60^{\circ}(\alpha=$ 
$\left.60^{\circ}\right)$ significantly reduced the capability of the cells to duplicate $(P<0.05)$ (Fig. 6b). This sample was previously classified as a mesoporous thin film since most of the identified pores have diameters between 5 and $50 \mathrm{~nm}$. Thus, the deposition of $\mathrm{ZnO}$ thin films with this pores' size distribution seems to improve the antifungal properties.

Analysing the CFUs counts (Fig. 6c), it was observed that after 8 hours of incubation these samples significantly inhibited viable cell growth by $58 \%\left(P<0.05\right.$ for $\mathrm{ZnO} 0^{\circ}$ and $P<0.01$ for $\mathrm{ZnO} \geq$ $40^{\circ}$ ), when compared to the control. Nevertheless, no significant differences were found using different incidence angles. After 25 hours of incubation $\mathrm{ZnO} \geq 40^{\circ}$ films significantly inhibited $(P$ $<0.001$ ) viable cell growth by $68 \%$, while the film $\mathrm{ZnO} 0^{\circ}$ did not promote a significant inhibition compared to the control. This suggests that $\mathrm{ZnO} 0^{\circ}$ only presented antifungal activity in the first 8 hours, losing that ability after 25 hours incubation.

Between 8 and 25 hours of incubation, the number of viable cells doubled in the presence of the control. In the presence of the $\mathrm{ZnO}$ thin films, significant inhibition was verified for the thin films prepared with inclined columns.

The antimicrobial activity of $\mathrm{ZnO}$ nanomaterials has been reported in several works [73-75]. However, despite all the efforts, the results are controversial and, until now, the exact mechanism behind the action of $\mathrm{ZnO}$ against microorganisms remains unknown [2]. In this regard, (i) physical interactions with the microorganisms, (ii) release of zinc ions $\left(\mathrm{Zn}^{2+}\right)$ and (iii) reactive oxygen species formation are put forward in the literature as the possible $\mathrm{ZnO}$ antimicrobial mechanisms. Moreover, these mechanisms might be related to each other and in many cases may occur simultaneously [76].

From the results above, it was suggested that the thin films' surface porosity plays an important role in the antimicrobial action. In fact, the existence of surface pores diameters between 5 and 50 
$\mathrm{nm}$ (mesopores) reduced significantly the capability of the cells to duplicate. This surface characteristics, resulting from the formation of inclined columns, are likely to be the optimal conditions to improve the direct contact between the fungal cells and the $\mathrm{ZnO}$ films. Therefore, indirectly, the mesopores allow to improve the antimicrobial action of the $\mathrm{ZnO}$, though through molecular mechanisms that are still under discussion.

\section{Conclusions}

Zinc oxide thin films were deposited by reactive magnetron sputtering, using the GLAD approach, at different incidence angles $\left(\alpha=0^{\circ}, 40^{\circ}, 60^{\circ}\right.$ and $\left.80^{\circ}\right)$, in order to evaluate the influence of microstructural-induced changes on their antifungal properties against the pathogenic fungus Candida albicans.

The morphological analysis showed thin films with inclined columns and modifications in the surface porosity. The different incidence angles originated different types of porous, namely distributions of micro, meso- and macropores in the thin films, from lower incidence angles towards higher angles. The $\mathrm{ZnO}$ thin films are highly transparent in the optical range, with the most noticeable feature occurring when the transmittance suffers a cut-off $(\lambda \sim 380 \mathrm{~nm})$ due to interband transitions (bandgap region). Nevertheless, some minor changes on the amplitude of interference fringes were perceivable, mainly due to changes of the refractive index, which are the result of a decrease of the material's density induced by the porosity changes. Regarding the structure of the films, there was also a loss of crystallinity for the highest incidence angle of $80^{\circ}$, since the shadowing effect hinders the grain growth.

All the thin films produced with incidence angles of $\alpha \geq 40^{\circ}$ showed significant antifungal activity, demonstrating a strong capability to inhibit cells growth. Furthermore, the type of pores seems to 
be related to antimicrobial activity. In fact, the surface of the thin film prepared with an angle of $60^{\circ}$ is typically featured by mesopores, which showed a higher influence on cellular growth. Therefore, it is possible to conclude that a mesoporous $\mathrm{ZnO}$ thin film might be the most adequate to inhibit the growth and proliferation of tested fungus (Candida albicans).

\section{Acknowledgements}

This work was supported by the Portuguese Foundation for Science and Technology (FCT) in the framework of the Strategic Funding UID/FIS/04650/2019 and UID/BIA/04050/2013; and by the projects NANOSENSING POCI-01-0145-FEDER-016902, with FCT reference PTDC/FISNAN/1154/2014; and project NANO4BIO POCI-01-0145-FEDER-032299, with FCT reference PTDC/FIS-MAC/32299/2017. Augusto Costa-Barbosa, Diogo Costa and Marco S. Rodrigues acknowledge FCT for their PhD Scholarships, SFRH/BD/133513/2017, SFRH/BD/136279/2018 and SFRH/BD/118684/2016, respectively. Joel Borges acknowledges FCT for his Researcher Contract from project NANO4BIO, CTTI-149/18-CF(1).

\section{References}

[1] N. Beyth, Y. Houri-Haddad, A. Domb, W. Khan, R. Hazan, Alternative Antimicrobial Approach: Nano-Antimicrobial Materials, Evidence-Based Complement. Altern. Med. 2015 (2015) 1-16. doi:10.1155/2015/246012.

[2] A. Sirelkhatim, S. Mahmud, A. Seeni, N.H.M. Kaus, L.C. Ann, S.K.M. Bakhori, H. Hasan, D. Mohamad, Review on zinc oxide nanoparticles: Antibacterial activity and toxicity mechanism, Nano-Micro Lett. 7 (2015) 219-242. doi:10.1007/s40820-015-0040-x.

[3] I. Perelshtein, A. Lipovsky, N. Perkas, T. Tzanov, M. Arguirova, M. Leseva, A. Gedanken, Making the hospital a safer place by sonochemical coating of all its textiles with antibacterial nanoparticles, Ultrason. Sonochem. 25 (2015). doi:10.1016/j.ultsonch.2014.12.012.

[4] S. Gatermann, R. Funfstuck, W. Handrick, L. Leitritz, K. Naber, A. Podbielski, MIQ 02: Urinary Tract Infections: Quality standards for microbiological infections, Munchen: Urban \& Fischer. 
(2005) 8-21.

[5] J. Richardson, J. Naglik, Special Issue: Mucosal Fungal Infections, J. Fungi. 4 (2018) 43. doi:10.3390/jof4020043.

[6] I. V Ene, S.-C. Cheng, M.G. Netea, A.J.P. Brown, Growth of Candida albicans cells on the physiologically relevant carbon source lactate affects their recognition and phagocytosis by immune cells., Infect. Immun. 81 (2013) 238-48. doi:10.1128/IAI.01092-12.

[7] L. Yan, C. Yang, J. Tang, Disruption of the intestinal mucosal barrier in Candida albicans infections, Microbiol. Res. 168 (2013) 389-395. doi:10.1016/j.micres.2013.02.008.

[8] P. Eggimann, J. Garbino, D. Pittet, Epidemiology of Candida species infections in critically ill non-immunosuppressed patients, Lancet Infect. Dis. 3 (2003) 685-702. doi:10.1016/S14733099(03)00801-6.

[9] CDC, Antibiotic resistance threats in the United States, 2013, Current. (2013) 114. doi:CS239559B.

[10] H. Wisplinghoff, T. Bischoff, S.M. Tallent, H. Seifert, R.P. Wenzel, M.B. Edmond, Nosocomial Bloodstream Infections in US Hospitals: Analysis of 24,179 Cases from a Prospective Nationwide Surveillance Study, Clin. Infect. Dis. 39 (2004) 309-317. doi:10.1086/421946.

[11] S. Costa-de-Oliveira, C. Pina-Vaz, D. Mendonça, A. Gonçalves Rodrigues, A first Portuguese epidemiological survey of fungaemia in a university hospital, Eur. J. Clin. Microbiol. Infect. Dis. 27 (2008) 365-374. doi:10.1007/s10096-007-0448-4.

[12] R. Sabino, C. Verissima, J. Brandão, C. Alves, H. Parada, L. Rosado, E. Paixão, Z. Videira, T. Tendeiro, P. Sampaio, C. Pais, Epidemiology of candidemia in oncology patients: A 6-year survey in a Portuguese central hospital, Med. Mycol. 48 (2010) 346-354.

doi:10.3109/13693780903161216.

[13] R.A. Weinstein, B. Hota, Contamination, Disinfection, and Cross-Colonization: Are Hospital Surfaces Reservoirs for Nosocomial Infection?, Clin. Infect. Dis. 39 (2004) 1182-1189. doi:10.1086/424667.

[14] V. Jašková, L. Hochmannová, J. Vytřasová, TiO 2 and ZnO Nanoparticles in Photocatalytic and Hygienic Coatings, Int. J. Photoenergy. 2013 (2013) 1-6. doi:10.1155/2013/795060.

[15] M.E. Davey, G.A. O'toole, Microbial biofilms: from ecology to molecular genetics., Microbiol. Mol. Biol. Rev. 64 (2000) 847-67.

[16] K. Page, M. Wilson, I.P. Parkin, Antimicrobial surfaces and their potential in reducing the role of the inanimate environment in the incidence of hospital-acquired infections, J. Mater. Chem. 19 (2009) 3819. doi:10.1039/b818698g.

[17] M.F. Elkady, H. Shokry Hassan, E.E. Hafez, A. Fouad, Construction of Zinc Oxide into Different Morphological Structures to Be Utilized as Antimicrobial Agent against Multidrug Resistant Bacteria, Bioinorg. Chem. Appl. 2015 (2015). doi:10.1155/2015/536854.

[18] A. Nel, T. Xia, L. Mädler, N. Li, Toxic potential of materials at the nanolevel, Science (80-. ). 311 (2006) 622-627. doi:10.1126/science.1114397.

[19] S. Stankic, S. Suman, F. Haque, J. Vidic, Pure and multi metal oxide nanoparticles: Synthesis, antibacterial and cytotoxic properties, J. Nanobiotechnology. 14 (2016). doi:10.1186/s12951-0160225-6. 
[20] Z.R. Khan, M.S. Khan, M. Zulfequar, M.S. Khan, Optical and Structural Properties of ZnO Thin Films Fabricated by Sol-Gel Method, Mater. Sci. Appl. 2 (2011) 340-345. doi:10.4236/msa.2011.25044.

[21] O. Oprea, E. Andronescu, D. Ficai, A. Ficai, F. Oktar, M. Yetmez, ZnO Applications and Challenges, Curr. Org. Chem. 18 (2014). doi:10.2174/13852728113176660143.

[22] N. Jones, B. Ray, K.T. Ranjit, A.C. Manna, Antibacterial activity of ZnO nanoparticle suspensions on a broad spectrum of microorganisms, FEMS Microbiol. Lett. 279 (2008) 71-76. doi:10.1111/j.1574-6968.2007.01012.x.

[23] A. Lipovsky, Y. Nitzan, A. Gedanken, R. Lubart, Antifungal activity of ZnO nanoparticles - the role of ROS mediated cell injury, Nanotechnology. 22 (2011) 105101. doi:10.1088/0957$4484 / 22 / 10 / 105101$.

[24] L.K. Adams, D.Y. Lyon, P.J.J. Alvarez, Comparative eco-toxicity of nanoscale TiO2, SiO2, and $\mathrm{ZnO}$ water suspensions, Water Res. 40 (2006) 3527-3532. doi:10.1016/j.watres.2006.08.004.

[25] H. Upadhyaya, S. Shome, R. Sarma, S. Tewari, M.K. Bhattacharya, S. Kumar Panda, Green Synthesis, Characterization and Antibacterial Activity of ZnO Nanoparticles, Am. J. Plant Sci. 9 (2018) 1279-1291. doi:10.4236/ajps.2018.96094.

[26] H. Meruvu, M. Vangalapati, S.C. Chippada, S. Rao Bammidi, Synthesis and characterization of zinc oxide nanoparticles and its antimicrobial activity against Bacillus subtilis and Escherichia coli, Rasayan J. Chem. 4 (2011) 217-222.

[27] S. Asgari, A. Jafari, Glob J Nanomed ZnO Nanostructure Deposition on Si Substrates by Chemical Vapor Deposition and its Antibacterial effect on Escherichia coli, Res. Artic. 1 (2017). doi:10.19080/GJN.2017.01.555570.

[28] D. Stoyanova, I. Ivanova, O. Angelov, T. Vladkova, Antibacterial activity of thin films TiO2 doped with Ag and $\mathrm{Cu}$ on Gracilicutes and Firmicutes bacteria, Biodiscovery. 20 (2017) e15076. doi:10.3897/biodiscovery.20.e15076.

[29] N. Talebian, S.M. Amininezhad, M. Doudi, Controllable synthesis of $\mathrm{ZnO}$ nanoparticles and their morphology-dependent antibacterial and optical properties, J. Photochem. Photobiol. B Biol. 120 (2013) 66-73. doi:10.1016/j.jphotobiol.2013.01.004.

[30] M. Malini, M. Thirumavalavan, W.-Y. Yang, J.-F. Lee, G. Annadurai, A versatile chitosan/ZnO nanocomposite with enhanced antimicrobial properties, Int. J. Biol. Macromol. 80 (2015) 121129. doi:10.1016/j.ijbiomac.2015.06.036.

[31] P. Carvalho, P. Sampaio, S. Azevedo, C. Vaz, J.P. Espinós, V. Teixeira, J.O. Carneiro, Influence of thickness and coatings morphology in the antimicrobial performance of zinc oxide coatings, Appl. Surf. Sci. 307 (2014) 548-557. doi:10.1016/j.apsusc.2014.04.072.

[32] J. Sawai, H. Igarashi, A. Hashimoto, T. Kokugan, M. Shimizu, Evaluation of growth inhibitory effect of ceramics powder slurry on bacteria by conductance method., J. Chem. Eng. JAPAN. 28 (1995) 288-293. doi:10.1252/jcej.28.288.

[33] J. Sawai, Quantitative evaluation of antibacterial activities of metallic oxide powders ( $\mathrm{ZnO}, \mathrm{MgO}$ and $\mathrm{CaO}$ ) by conductimetric assay., J. Microbiol. Methods. 54 (2003) 177-82. doi:10.1016/S01677012(03)00037-X.

[34] P. Filipe, J.N. Silva, R. Silva, J.L. Cirne de Castro, M. Marques Gomes, L.C. Alves, R. Santus, T. Pinheiro, Stratum Corneum Is an Effective Barrier to TiO2 and ZnO Nanoparticle Percutaneous 
Absorption, Skin Pharmacol. Physiol. 22 (2009) 266-275. doi:10.1159/000235554.

[35] V. Sharma, R.K. Shukla, N. Saxena, D. Parmar, M. Das, A. Dhawan, DNA damaging potential of zinc oxide nanoparticles in human epidermal cells., Toxicol. Lett. 185 (2009) 211-8. doi:10.1016/j.toxlet.2009.01.008.

[36] C.M. Sayes, K.L. Reed, D.B. Warheit, Assessing Toxicity of Fine and Nanoparticles: Comparing In Vitro Measurements to In Vivo Pulmonary Toxicity Profiles, Toxicol. Sci. 97 (2007) 163-180. doi:10.1093/toxsci/kfm018.

[37] W.-S. Cho, R. Duffin, C.A. Poland, S.E.M. Howie, W. MacNee, M. Bradley, I.L. Megson, K. Donaldson, Metal Oxide Nanoparticles Induce Unique Inflammatory Footprints in the Lung: Important Implications for Nanoparticle Testing, Environ. Health Perspect. 118 (2010) 16991706. doi:10.1289/ehp.1002201.

[38] A. Boxall, Q. Chaudhry, C. Sinclair, A. Jones, R. Aitken, B. Jefferson, C. Watts, Current and future predicted environmental exposure to engineered nanoparticles, York, UK, 2007.

[39] V.D. Rajput, T.M. Minkina, A. Behal, S.N. Sushkova, S. Mandzhieva, R. Singh, A. Gorovtsov, V.S. Tsitsuashvili, W.O. Purvis, K.A. Ghazaryan, H.S. Movsesyan, Effects of zinc-oxide nanoparticles on soil, plants, animals and soil organisms: A review, Environ. Nanotechnology, Monit. Manag. 9 (2018) 76-84. doi:10.1016/J.ENMM.2017.12.006.

[40] M. Ohring, Materials science of thin films : deposition and structure, Academic Press, 2002.

[41] P.J. Kelly, R.D. Arnell, Magnetron sputtering: a review of recent developments and applications, Vacuum. 56 (2000) 159-172. doi:10.1016/S0042-207X(99)00189-X.

[42] D. Maurya, A. Sardarinejad, K. Alameh, D.K. Maurya, A. Sardarinejad, K. Alameh, Recent Developments in R.F. Magnetron Sputtered Thin Films For pH Sensing Applications -An Overview, 4 (2014) 756-771. doi:10.3390/coatings4040756.

[43] A. Barranco, A. Borras, A.R. Gonzalez-Elipe, A. Palmero, Perspectives on oblique angle deposition of thin films: From fundamentals to devices, Prog. Mater. Sci. 76 (2016) 59-153. doi:10.1016/j.pmatsci.2015.06.003.

[44] T.G. Knorr, R.W. Hoffman, Dependence of Geometric Magnetic Anisotropy in Thin Iron Films, Phys. Rev. 113 (1959) 1039-1046. doi:10.1103/PhysRev.113.1039.

[45] M.T. Taschuk, M.M. Hawkeye, M.J. Brett, Glancing Angle Deposition, Third Edit, Elsevier Ltd., 2010. doi:10.1016/B978-0-8155-2031-3.00013-2.

[46] M.M. Hawkeye, M.T. Taschuk, M.J. Brett, Glancing Angle Deposition Technology, in: Glancing Angle Depos. Thin Film. Eng. Nanoscale, First Edit, John Wiley \& Sons, Ltd., 2014: pp. 1-30.

[47] M.M. Hawkeye, M.J. Brett, Glancing angle deposition: Fabrication, properties, and applications of micro- and nanostructured thin films, J. Vac. Sci. Technol. A Vacuum, Surfaces, Film. 25 (2007) 1317. doi:10.1116/1.2764082.

[48] S. Liedtke, C. Grüner, A. Lotnyk, B. Rauschenbach, Glancing angle deposition of sculptured thin metal films at room temperature, Nanotechnology. 28 (2017) 385604. doi:10.1088/13616528/aa7a79.

[49] P. Salazar, F.J. Garcia-Garcia, F. Yubero, J. Gil-Rostra, A.R. González-Elipe, Characterization and application of a new $\mathrm{pH}$ sensor based on magnetron sputtered porous WO3 thin films deposited at oblique angles, Electrochim. Acta. 193 (2016) 24-31. 
doi:10.1016/J.ELECTACTA.2016.02.040.

[50] J. Yuan, B. Wang, H. Wang, Y. Chai, Y. Jin, H. Qi, J. Shao, Electrochromic behavior of WO3 thin films prepared by GLAD, Appl. Surf. Sci. 447 (2018) 471-478.

doi:10.1016/J.APSUSC.2018.03.248.

[51] M. Horprathum, T. Srichaiyaperk, B. Samransuksamer, A. Wisitsoraat, P. Eiamchai, S. Limwichean, C. Chananonnawathorn, K. Aiempanakit, N. Nuntawong, V. Patthanasettakul, C. Oros, S. Porntheeraphat, P. Songsiriritthigul, H. Nakajima, A. Tuantranont, P. Chindaudom, Ultrasensitive Hydrogen Sensor Based on Pt-Decorated WO3 Nanorods Prepared by GlancingAngle dc Magnetron Sputtering, ACS Appl. Mater. Interfaces. 6 (2014) 22051-22060. doi:10.1021/am505127g.

[52] M.S. Rodrigues, J. Borges, M. Proença, P. Pedrosa, N. MARTIN, K. Romanyuk, A.L. Kholkin, F. Vaz, Nanoplasmonic response of porous $\mathrm{Au}-\mathrm{TiO} 2$ thin films prepared by oblique angle deposition, Nanotechnology. (2019). doi:10.1088/1361-6528/ab068e.

[53] K. Robbie, G. Beydaghyan, T. Brown, C. Dean, J. Adams, C. Buzea, Ultrahigh vacuum glancing angle deposition system for thin films with controlled three-dimensional nanoscale structure, Rev. Sci. Instrum. 75 (2004) 1089-1097. doi:10.1063/1.1667254.

[54] A. Ferreira, P. Pedrosa, N. Martin, M.A.P. Yazdi, A. Billard, S. Lanceros-Méndez, F. Vaz, Nanostructured Ti1-xCux thin films with tailored electrical and morphological anisotropy, Thin Solid Films. 672 (2019) 47-54. doi:10.1016/j.tsf.2019.01.008.

[55] M.S. Rodrigues, D. Costa, R.P. Domingues, M. Apreutesei, P. Pedrosa, N. Martin, V.M. Correlo, R.L. Reis, E. Alves, N.P. Barradas, P. Sampaio, J. Borges, F. Vaz, Optimization of nanocomposite $\mathrm{Au} / \mathrm{TiO} 2$ thin films towards LSPR optical-sensing, Appl. Surf. Sci. 438 (2018) 74-83. doi:10.1016/j.apsusc.2017.09.162.

[56] P. Pedrosa, A. Ferreira, N. Martin, M. Arab Pour Yazdi, A. Billard, S. Lanceros-Méndez, F. Vaz, Nano-sculptured Janus-like TiAg thin films obliquely deposited by GLAD co-sputtering for temperature sensing, Nanotechnology. 29 (2018) 355706. doi:10.1088/1361-6528/aacba8.

[57] R. El Beainou, A. Chargui, P. Pedrosa, A. Mosset, S. Euphrasie, P. Vairac, N. Martin, Electrical resistivity and elastic wave propagation anisotropy in glancing angle deposited tungsten and gold thin films, Appl. Surf. Sci. 475 (2019) 606-614. doi:10.1016/J.APSUSC.2019.01.041.

[58] A. Ferreira, N. Martin, S. Lanceros-Méndez, F. Vaz, Tuning electrical resistivity anisotropy of ZnO thin films for resistive sensor applications, Thin Solid Films. 654 (2018) 93-99. doi:10.1016/j.tsf.2018.03.090.

[59] M.S. Rodrigues, J. Borges, M. Proença, P. Pedrosa, N. MARTIN, K. Romanyuk, A.L. Kholkin, F. Vaz, Nanoplasmonic response of porous $\mathrm{Au}-\mathrm{TiO} 2$ thin films prepared by oblique angle deposition, Nanotechnology. 30 (2019) 225701. doi:10.1088/1361-6528/ab068e.

[60] N.P. Barradas, C. Jeynes, R.P. Webb, U. Kreissig, R. Grötzschel, Unambiguous automatic evaluation of multiple Ion Beam Analysis data with Simulated Annealing, Nucl. Instruments Methods Phys. Res. Sect. B Beam Interact. with Mater. Atoms. 149 (1999) 233-237. doi:10.1016/S0168-583X(98)00731-9.

[61] N.P. Barradas, C. Pascual-Izarra, Double scattering in RBS analysis of PtSi thin films on Si, Nucl. Instruments Methods Phys. Res. Sect. B Beam Interact. with Mater. Atoms. 228 (2005) 378-382. doi:https://doi.org/10.1016/j.nimb.2004.10.074.

[62] N.P. Barradas, M.A. Reis, Accurate calculation of pileup effects in PIXE spectra from first 
principles, X-Ray Spectrom. 35 (2006) 232-237. doi:10.1002/xrs.903.

[63] J.M. Khoshman, J.N. Hilfiker, N. Tabet, M.E. Kordesch, Multiple oscillator models for the optical constants of polycrystalline zinc oxide thin films over a wide wavelength range, Appl. Surf. Sci. 307 (2014) 558-565. doi:10.1016/J.APSUSC.2014.04.073.

[64] Z. Qiao, C. Agashe, D. Mergel, Dielectric modeling of transmittance spectra of thin ZnO:Al films, Thin Solid Films. 496 (2006) 520-525. doi:10.1016/J.TSF.2005.08.282.

[65] M. Caglar, S. Ilican, Y. Caglar, F. Yakuphanoglu, Electrical conductivity and optical properties of ZnO nanostructured thin film, Appl. Surf. Sci. 255 (2009) 4491-4496. doi:10.1016/J.APSUSC.2008.11.055.

[66] D. Toledano, R.E. Galindo, M. Yuste, J.M. Albella, O. Sánchez, Compositional and structural properties of nanostructured $\mathrm{ZnO}$ thin films grown by oblique angle reactive sputtering deposition: effect on the refractive index, J. Phys. D. Appl. Phys. 46 (2013) 045306. doi:10.1088/0022$3727 / 46 / 4 / 045306$.

[67] Y. Yang, X.W. Sun, B.J. Chen, C.X. Xu, T.P. Chen, C.Q. Sun, B.K. Tay, Z. Sun, Refractive indices of textured indium tin oxide and zinc oxide thin films, Thin Solid Films. 510 (2006) 95101. doi:10.1016/j.tsf.2005.12.265.

[68] S. Amirhaghi, V. Craciun, D. Craciun, J. Elders, I.W. Boyd, Low temperature growth of highly transparent c-axis oriented $\mathrm{ZnO}$ thin films by pulsed laser deposition, Microelectron. Eng. 25 (1994) 321-326. doi:10.1016/0167-9317(94)90032-9.

[69] N. Fujimura, T. Nishihara, S. Goto, J. Xu, T. Ito, Control of preferred orientation for ZnOx films: control of self-texture, J. Cryst. Growth. 130 (1993) 269-279. doi:10.1016/0022-0248(93)90861P.

[70] J. Chu, X. Peng, M. Sajjad, B. Yang, P.X. Feng, Nanostructures and sensing properties of ZnO prepared using normal and oblique angle deposition techniques, Thin Solid Films. 520 (2012) 3493-3498. doi:10.1016/J.TSF.2011.12.066.

[71] Y. Tamar, M. Tzabari, C. Haspel, Y. Sasson, Estimation of the porosity and refractive index of sol-gel silica films using high resolution electron microscopy, Sol. Energy Mater. Sol. Cells. 130 (2014) 246-256. doi:10.1016/j.solmat.2014.07.020.

[72] J. Rouquerol, D. Avnir, C.W. Fairbridge, D.H. Everett, J.M. Haynes, N. Pernicone, J.D.F. Ramsay, K.S.W. Sing, K.K. Unger, Recommendations for the characterization of porous solids (Technical Report), Pure Appl. Chem. 66 (1994) 1739-1758. doi:10.1351/pac199466081739.

[73] K. Kairyte, A. Kadys, Z. Luksiene, Antibacterial and antifungal activity of photoactivated ZnO nanoparticles in suspension, J. Photochem. Photobiol. B Biol. 128 (2013) 78-84. doi:10.1016/j.jphotobiol.2013.07.017.

[74] N. Jones, B. Ray, K.T. Ranjit, A.C. Manna, Antibacterial activity of ZnO nanoparticle suspensions on a broad spectrum of microorganisms, FEMS Microbiol. Lett. 279 (2008) 71-76. doi:10.1111/j.1574-6968.2007.01012.x.

[75] Y.H. Leung, C.M.N. Chan, A.M.C. Ng, H.T. Chan, M.W.L. Chiang, A.B. Djurišić, Y.H. Ng, W.Y. Jim, M.Y. Guo, F.C.C. Leung, W.K. Chan, D.T.W. Au, Antibacterial activity of ZnO nanoparticles with a modified surface under ambient illumination, Nanotechnology. 23 (2012) 475703. doi:10.1088/0957-4484/23/47/475703.

[76] R. Kumar, A. Umar, G. Kumar, H.S. Nalwa, Antimicrobial properties of ZnO nanomaterials: A 
review, Ceram. Int. 43 (2017). doi:10.1016/j.ceramint.2016.12.062. 


\section{Figure Captions}

Figure 1 - Schematic representation of a) custom-made reactive DC magnetron sputtering system equipped with the GLAD sample holder and b) inclined $\mathrm{ZnO}$ thin films, obtained by changing the incidence angle $(\alpha)$ between depositions.

Figure 2 - Transmittance spectra of the $\mathrm{ZnO}$ thin films as a function of the incidence angle.

Figure 3 - Crystalline evolution of the $\mathrm{ZnO}$ thin films as a function of incidence angle.

Figure 4 - Cross-section micrographs showing the morphological evolution of the $\mathrm{ZnO}$ thin films as a function of incidence angle.

Figure 5 - Surface characterization of the $\mathrm{ZnO}$ thin films produced using GLAD configuration at $\alpha=0^{\circ}, 40^{\circ}, 60^{\circ}$ and $80^{\circ}$; a) SEM top-view micrographs; b) surface porosity calculation using an algorithm implemented in MATLAB and c) Feret diameter histogram.

Figure 6 - Influence of incidence angle of $\mathrm{ZnO}$ thin films on cell growth of Candida albicans. a) optical density (O.D. 600nm) during the 25 hours of incubation; b) specific growth rate $\left(\mathrm{h}^{-1}\right)$ for yeast cultures; c) number of CFUs counted in selected time points, 8 and 25 hours of incubation. One, two, three and four * correspond to $P<0.05, P<0.01, P<0.001$ and $P<0.0001$, respectively. 